\title{
Zinc Based Metal-Organic Frameworks as Ofloxacin Adsorbents in Polluted Waters: ZIF-8 vs. $\mathrm{Zn}_{3}(\mathrm{BTC})_{2}$
}

\author{
Doretta Capsoni $^{1}{ }^{(\mathbb{D}}$, Giulia Guerra ${ }^{2}$, Constantin Puscalau ${ }^{1,3}$, Federica Maraschi ${ }^{2} \mathbb{D}$, Giovanna Bruni ${ }^{1}$ (D), \\ Francesco Monteforte ${ }^{1}$, Antonella Profumo ${ }^{2}$ (D) and Michela Sturini ${ }^{2, *(D)}$
}

1 C.S.G.I. (Consorzio Interuniversitario per lo Sviluppo dei Sistemi a Grande Interfase) \& Department of Chemistry, Physical Chemistry Section, University of Pavia, 27100 Pavia, Italy; doretta.capsoni@unipv.it (D.C.); constantin.puscalau@nottingham.ac.uk (C.P.); giovanna.bruni@unipv.it (G.B.); francesco.monteforte01@universitadipavia.it (F.M.)

2 Department of Chemistry, University of Pavia, 27100 Pavia, Italy; giulia.guerra01@universitadipavia.it (G.G.); federica.maraschi@unipv.it (F.M.); antonella.profumo@unipv.it (A.P.)

3 The GlaxoSmithKline Neutral Laboratories for Sustainable Chemistry, University of Nottingham, Jubilee Campus, Nottingham NG7 2TU, UK

* Correspondence: michela.sturini@unipv.it; Tel.: +39-0382-987347

Citation: Capsoni, D.; Guerra, G.; Puscalau, C.; Maraschi, F.; Bruni, G.; Monteforte, F.; Profumo, A.; Sturini, M. Zinc Based Metal-Organic Frameworks as Ofloxacin Adsorbents in Polluted Waters: ZIF-8 vs. $\mathrm{Zn}_{3}(\mathrm{BTC})_{2}$. Int. J. Environ. Res. Public Health 2021, 18, 1433. https:// doi.org/10.3390/ijerph18041433

Academic Editor: Daniela Varrica Received: 29 December 2020

Accepted: 31 January 2021

Published: 3 February 2021

Publisher's Note: MDPI stays neutral with regard to jurisdictional claims in published maps and institutional affiliations.

Copyright: (C) 2021 by the authors Licensee MDPI, Basel, Switzerland. This article is an open access article distributed under the terms and conditions of the Creative Commons Attribution (CC BY) license (https:/ / creativecommons.org/licenses/by/ $4.0 /)$.

\begin{abstract}
Two different zinc-based metal-organic frameworks (MOFs) were investigated to remove one of the most used fluoroquinolone antibiotic, Ofloxacin (OFL), from polluted water. The most common zeolitic imidazolate framework-8 (ZIF-8) and the green $\mathrm{Zn}(\mathrm{II})$ and benzene-1,3,5-tri-carboxylate $\left(\mathrm{Zn}_{3}(\mathrm{BTC})_{2}\right)$ were prepared through a facile synthetic route and characterized by means of FourierTransform Infrared (FT-IR) Spectroscopy, X-ray Powder Diffraction (XRPD), and Scanning Electron Microscopy (SEM) analyses. The two MOFs were compared in terms of both adsorption and kinetic aspects under real conditions (tap water, natural $\mathrm{pH}$ ). Results showed that OFL was adsorbed in remarkable amounts, $95 \pm 10$ and $25.3 \pm 0.8 \mathrm{mg} \mathrm{g}^{-1}$ on ZIF- 8 and $\mathrm{Zn}_{3}(\mathrm{BTC})_{2}$, respectively, following different mechanisms. Specifically, a Langmuir model well described the ZIF-8 profile, while for $\mathrm{Zn}_{3}(\mathrm{BTC})_{2}$, cooperative adsorption occurred. Moreover the kinetic results were quite different, pseudo-second-order and sigmoidal, respectively. The suitability of ZIF- 8 and $\mathrm{Zn}_{3}(\mathrm{BTC})_{2}$ as adsorbent phases for water depollution was tested on tap water samples spiked with OFL $10 \mu \mathrm{g} \mathrm{L}^{-1}$. The obtained removal efficiencies, of $88 \%$ for ZIF-8 and $72 \%$ for $\mathrm{Zn}_{3}(\mathrm{BTC})_{2}$, make these materials promising candidates for removing fluoroquinolone antibiotics (FQs) from polluted waters, notwithstanding their limited reusability in tap water, as demonstrated by in-depth characterization of the two MOFs after usage.
\end{abstract}

Keywords: fluoroquinolone antibiotic; zinc-based metal-organic frameworks; adsorption; wastewater treatment; MOFs reusability; polluted waters

\section{Introduction}

The widespread diffusion of antibiotics in the environment, especially in the aquatic one, is a compelling issue. Indeed, they have been widely detected, mainly in their native form, in wastewater, surface water, drinking water, and soils in most, if not all, developed countries, especially those close to highly urbanized areas [1,2]. Detailed monitoring, carried out on influents and effluents from different urban wastewater treatment plants (WWTPs), located in urbanized and industrialized areas, on rivers that directly receive the discharge from plants, and on those located around the city, demonstrated that standard wastewater treatment plants are ineffective in removing such highly persistent emerging contaminants (EC) [1,2]. Consequently, antibiotic residues re-enter the hydrogeological cycle after the treatment at concentrations ranging from a few tens to hundreds of nanograms per liter [2-5]. These low concentrations are, however, high enough to cause well-known collateral effects, such as the generation of antibiotic-resistant bacteria (ARB) 
and antibiotic-resistant genes (ARG) $[1,6]$. It has been recently reported that reducing antibiotics consumption would not be enough to slow down the dissemination of resistance [6]. For this reason, the recent EU directive (2015/495/EU) has been updated (2018/840/EU), both to implement the current legislation and provide new proposals, such as the "action plan against the rising threats from antimicrobial resistance" specifically intended to regularly monitor antibiotics and, as well as, to reduce their widespread distribution [1].

Currently, there is an increasing commitment to finding efficient processes for the removal of antibiotic residues before they enter the aquatic compartment. Different treatment processes, both biological and physicochemical, have been proposed to improve conventional WWTPs [7]. The biological ones have been mainly used for antibiotic removal from wastewater and sludge. In contrast, the further ones, such as activated carbon adsorption, ozonization, advanced oxidation methods, nanofiltration, etc., have been tested for surface and drinking waters and wastewater effluents ([7] and references therein). A promising option is represented by the adsorption process that indeed is a good choice due to the many advantages it offers: (i) Low cost, (ii) sustainability, (iii) no generation of toxic byproducts, (iv) easy to integrate to conventional WWTPs, (v) easy to manage and maintain, (vi) possibility to exploit new adsorbent phases [7].

Over the last decade, research and development of new adsorbent materials have been expanded upon. A detailed examination of the literature has shown that different substrates, both natural and properly synthesized or modified, such as activated carbons, biochar from low-cost materials, functionalized nanotube, graphene oxide, mesoporous carbons, and clay minerals were used for antibiotic adsorption [7-10]. Interestingly, the recent employment of metal-organic frameworks (MOFs) as adsorbent phases makes them an alternative and a promising option for remediation of polluted waters [11-13]. MOFs consist of metal transition ions orderly linked to organic ligands. Besides their intrinsic properties (high surface area and porous structure), they have different functionalities, making them versatile materials. In this way, they can adequately interact with different molecules through electrostatic interactions, H-bonding, hydrophobic interaction, and $\pi-\pi$ stacking. Several MOFs have been recently employed for drug remediation, such as H-KUST 1 (H-KUST: Hong Kong University of Science and Technology), MIL-53, MIL-100, MIL-101 (MIL: Materiaux de l'Institut Lavoisier), UiO-66 (UiO: Universitetet i Oslo), and ZIFs (ZIF: Zeolitic Imidazolate Framework), showing remarkable affinities towards those organic molecules [14-23]. However, the effect of some key parameters, such as the use of water not previously purified, natural $\mathrm{pH}$, and $\mu \mathrm{g}$ per liter drug concentration, seems not to have been deeply investigated yet.

Thus, we deemed it appropriate to study and compare the efficiency of two different zinc-based metal-organic frameworks, the largely used zeolitic imidazolate framework-8 (ZIF-8) and the $\mathrm{Zn}$ (II) and benzene-1,3,5-tri-carboxylate $\left(\mathrm{Zn}_{3}(\mathrm{BTC})_{2}\right)$, for the removal of a widely used human antibiotic, Ofloxacin (OFL), under relevant real conditions, viz. tap water and low-level concentration. OFL was selected as a model molecule due to our previous investigation on fluoroquinolones (FQs) affinity towards natural and synthetic substrates [8-10]; ZIF-8 and $\mathrm{Zn}_{3}(\mathrm{BTC})_{2}$ are suitable for water remediation due to a nontoxic metal ion, $\mathrm{Zn}^{2+}$. ZIF- 8 displays a sodalite-type crystal structure and large pores with diameters of $11.6 \AA$ accessible through small apertures with a diameter of $3.4 \AA$ [24]. It is water-stable due to a strong coordination bond, according to the hard/soft acid/base theory [25]. Moreover, compared to other MOFs, it shows exceptional thermal and chemical stability [26] in aqueous and harsh environments. The high surface area and pore size make it attractive in lots of applications such as gas storage, separations, catalysis, drug delivery and chemical sensors [27]. $\mathrm{Zn}_{3}(\mathrm{BTC})_{2}$ was chosen for its high water solution stability, biocompatibility, and green synthesis (sonochemical process). Moreover, while already applied in molecular sensing [28] and drug delivery [29], to our knowledge, it was not yet used for water remediation. It displays a monoclinic crystal structure with ellipticallyshaped pores of $4 \times 5 \AA$ diameter [30]. To our knowledge, only in the case of ZIF-8, a recent study addressed the removal of OFL under controlled laboratory conditions [20], quite 
different from the ones mentioned above. In this study, the two MOFs were compared in terms of both adsorption and kinetic aspects under real conditions, micrograms per liter concentration, and tap water, not yet investigated, and, importantly, not yet fully characterized after use.

\section{Materials and Methods}

\subsection{Materials}

All the chemicals employed were reagent grade or higher in quality. OFL, ultrapure hydrochloric acid $(\mathrm{HCl}) 30 \%, \mathrm{Zn}\left(\mathrm{NO}_{3}\right)_{2} \cdot 6 \mathrm{H}_{2} \mathrm{O}$, 2-methylimidazole, $\mathrm{Zn}\left(\mathrm{CH}_{3} \mathrm{COO}\right)_{2} \cdot 2 \mathrm{H}_{2} \mathrm{O}$, and trimesic acid $\left(\mathrm{H}_{3} \mathrm{BTC}\right)$ were purchased from Merck (Milano, Italy). High Performance Liquid Chromatography (HPLC) gradient-grade acetonitrile (ACN) and absolute ethanol were purchased by VWR International (Milano, Italy), $\mathrm{H}_{3} \mathrm{PO}_{4}(85 \% \mathrm{w} / \mathrm{w})$, methanol for Liquid Chromatography Mass Spectrometry LC/MS, and water for LC/MS by Carlo Erba Reagents (Cornaredo, Milano, Italy). Aqueous OFL solution ( $305 \mathrm{mg} \mathrm{L}^{-1}$ ) was prepared in tap water and stored in the dark at $4{ }^{\circ} \mathrm{C}$ before use.

\subsection{Synthesis}

\subsubsection{ZIF-8}

ZIF-8 was synthesized by following the procedure reported by Pan et al. [31], the first example of ZIFs synthesis in a purely aqueous system. This synthetic approach was chosen becouse it is rapid and performed at room temperature. Compared to other synthesis routes reported in the literature to prepare ZIF-8 [27], it is not time-consuming and does not require organic solvents and high energy-consuming steps. A solution with $\mathrm{Zn}^{2+}$ :2-methylimidazole: $\mathrm{H}_{2} \mathrm{O}$ in 1:70:1238 molar ratio was prepared as follows. Firstly, $0.293 \mathrm{~g} \mathrm{Zn}\left(\mathrm{NO}_{3}\right)_{2} \cdot 6 \mathrm{H}_{2} \mathrm{O}$ was dissolved in $2 \mathrm{~g}$ distilled water (DI). Secondly, $5.675 \mathrm{~g}$ 2-methylimidazole was dissolved in $20 \mathrm{~g}$ DI water. The obtained solutions were then mixed and stirred at room temperature. The synthesis solution turned milky almost instantly after the two solutions were mixed. After stirring for $5 \mathrm{~min}$, the product was collected by centrifugation and washed with DI water several times. The obtained powder was dried at $70{ }^{\circ} \mathrm{C}$ overnight. The activation process was then carried out to remove the solvent molecules from the ZIF-8 pores: The powder was heated under vacuum at $80^{\circ} \mathrm{C}$ for $3 \mathrm{~h}$ and stored at room temperature in an Ar-filled dry-box (MBraun, Garching, Germany; $\left.\mathrm{O}_{2} \leq 1 \mathrm{ppm}, \mathrm{H}_{2} \mathrm{O} \leq 1 \mathrm{ppm}\right)$.

\subsection{2. $\mathrm{Zn}_{3}(\mathrm{BTC})_{2}$}

The $\mathrm{Zn}_{3}(\mathrm{BTC})_{2}$ was prepared following the sonochemical synthesis reported by Lestari et al. [29]. $3.133 \mathrm{~g} \mathrm{Zn}\left(\mathrm{CH}_{3} \mathrm{COO}\right)_{2} \cdot 2 \mathrm{H}_{2} \mathrm{O}$ was dissolved in $25 \mathrm{~mL}$ DI water, and $2 \mathrm{~g}$ trimesic acid was dissolved in $25 \mathrm{~mL}$ Ethanol (EtOH). The obtained solutions were mixed and sonicated for $60 \mathrm{~min}$. The obtained white precipitate was washed several times with EtOH and dried at room temperature overnight. No activation process was carried out due to the loss of crystallinity by treating the powder under vacuum at $80^{\circ} \mathrm{C}$, as demonstrated by $\mathrm{X}$-ray powder diffraction technique.

\subsection{Characterization Techniques}

X-ray powder diffraction (XRPD) measurements were performed by using a Bruker D5005 diffractometer with the $\mathrm{CuK} \alpha$ radiation (Bruker, Karlsruhe, Germany), graphite monochromator, and scintillation detector. The patterns were collected in the $5-25^{\circ}$ and $5-35^{\circ}$ angular range for the ZIF- 8 and $\mathrm{Zn}_{3}(\mathrm{BTC})_{2}$ samples, respectively, step size of $0.03^{\circ}$ and counting time of $4 \mathrm{~s} /$ step. A silicon low-background sample holder was used. An air-tight dome sample holder was used for the activated ZIF-8.

Fourier-Transform Infrared (FT-IR) spectra were obtained with a Nicolet FT-IR iS10 Spectrometer (Nicolet, Madison, WI, USA) equipped with an ATR (attenuated total reflectance) sampling accessory (Smart iTR with ZnSe plate) by co-adding 32 scans in the $4000-500 \mathrm{~cm}^{-1}$ range at $4 \mathrm{~cm}^{-1}$ resolution. 
Scanning Electron Microscopy (SEM) measurements were performed using a Zeiss EVO MA10 (Carl Zeiss, Oberkochen, Germany) Microscope. The SEM images were collected on gold-sputtered samples.

\subsection{Thermodynamic and Kinetic Studies}

\subsubsection{Thermodynamic Experiments}

OFL adsorption on the two MOFs was studied using a batch equilibration method. Antibiotic solutions in the range 8-305 $\mathrm{mg} \mathrm{L}^{-1}$ were prepared in tap water. Ten $\mathrm{mg}$ of each MOF was weighed into separated flasks and mixed with $20 \mathrm{~mL}$ of OFL solution. In the case of ZIF-8, the antibiotic solution was added using a syringe into the sealed flasks containing the activated adsorbent phase removed from the dry box before use, and the solution $\mathrm{pH}$ was adjusted around 8, adding $50 \mu \mathrm{L} 1 \mathrm{M} \mathrm{HCl}$. The flasks, wrapped with aluminum foils to prevent FQ light-induced decomposition, were shaken at $90 \mathrm{rpm}$ for $24 \mathrm{~h}$ at room temperature to ensure the equilibration. The suspensions were filtered through a $0.22 \mu \mathrm{m}$ nylon syringe filter and analyzed by HPLC-UV Shimadzu (Shimadzu Corporation, Milano, Italy) to determine OFL concentration at equilibrium $\left(C_{e}\right)$.

The following Equation (1) calculated the adsorbed OFL amount at equilibrium $\left(q_{e}, \mathrm{mg} \mathrm{g}^{-1}\right)$ :

$$
q_{e}=\frac{\left(C_{0}-C_{e}\right) \times V}{M}
$$

where $C_{0}$ is the initial OFL concentration $\left(\mathrm{mg} \mathrm{L}^{-1}\right), C_{e}$ the OFL concentration in solution at equilibrium $\left(\mathrm{mg} \mathrm{L}^{-1}\right), V$ the volume of the solution (L), and $M$ the amount of the adsorbent $(\mathrm{g})$.

All experiments were performed in triplicate with good reproducibility (RSD $\leq 10 \%)$.

No change in OFL concentration was detected in the control samples (tap water solutions containing OFL and no adsorbent phase).

The isotherm parameters were calculated by dedicated software (OriginPro, Version 2019b. OriginLab Corporation, Northampton, MA, USA).

\subsubsection{Kinetic Experiments}

Twenty mg of ZIF-8 and $20 \mathrm{mg}$ of $\mathrm{Zn}_{3}(\mathrm{BTC})_{2}$ were suspended in $40 \mathrm{~mL}$ of tap water at an initial OFL concentration of $36 \mathrm{mg} \mathrm{L}^{-1}$ and $12 \mathrm{mg} \mathrm{L}^{-1}$, respectively. OFL initial concentrations were chosen according to the thermodynamic results to guarantee an adsorption efficiency in the range of 10-85\%, as indicated in the guidelines ASTM D3860 [32]. As mentioned above, in the case of ZIF-8, the antibiotic solution was added using a syringe into the sealed flasks containing the activated adsorbent phase removed from the dry box before use. Then it was acidified, adding $50 \mu \mathrm{L} 1 \mathrm{M} \mathrm{HCl}$ to reach a $\mathrm{pH}$ value around 8 , while no $\mathrm{pH}$ modification was required for $\mathrm{Zn}_{3}(\mathrm{BTC})_{2}$ suspension. The suspensions were maintained under magnetic stirring $(700 \mathrm{rpm})$ throughout the experiment. One hundred $\mu \mathrm{L}$ supernatants were collected at planned times in the range 0-60 min, diluted to 5-10 $\mathrm{mL}$ tap water, filtered $(0.22 \mu \mathrm{m}$ nylon syringe filter), and injected in the HPLC-FD (Perkin Elmer, Milano, Italy) system to determine the OFL concentration at time $t\left(C_{t}\right)$.

The following Equation (2) calculated the adsorbed OFL amount at time $t\left(q_{t}, \mathrm{mg} \mathrm{g}^{-1}\right)$ :

$$
q_{t}=\frac{\left(C_{0}-C_{t}\right) \times V}{M}
$$

where $C_{0}$ is the initial OFL concentration ( $\left.\mathrm{mg} \mathrm{L}^{-1}\right), C_{t}$ the OFL concentration in solution at time $t\left(\mathrm{mg} \mathrm{L}^{-1}\right), V$ the volume of the solution $(\mathrm{L})$, and $M$ the amount of the adsorbent $(\mathrm{g})$.

All experiments were performed in triplicate with good reproducibility (RSD $\leq 10 \%$ ) No change in OFL concentration was detected in the control sample (tap water solutions containing OFL and no adsorbent phase).

The kinetic parameters were calculated by dedicated software (OriginPro, Version 2019b. OriginLab Corporation, Northampton, MA, USA). 


\subsection{Analytical Measurements}

For the adsorption experiments, an HPLC-UV Shimadzu (Shimadzu Corporation, Milano, Italy) system consisting of an LC-20AT solvent delivery module equipped with a DGU-20A3 degasser and interfaced with an SPD-20A UV detector, was used. The wavelength selected for analysis was $280 \mathrm{~nm}$ corresponding to the maximum OFL adsorption. Each sample was filtered $(0.22 \mu \mathrm{m})$ and injected $(20 \mu \mathrm{L})$ into a $250 \times 4.6 \mathrm{~mm}, 5 \mu \mathrm{m}$ KromaPhase 100 C18 (Scharlab, Riozzo di Cerro al Lambro, Milano, Italy) coupled with a similar guard-column. Isocratic elution was carried out by using a mobile phase $25 \mathrm{mM}$ $\mathrm{H}_{3} \mathrm{PO}_{4}-\mathrm{ACN}$ (85:15). The flow rate was $1.0 \mathrm{~mL} \mathrm{~min}^{-1}$.

Calibration with four standards at concentrations between 1 and $10 \mathrm{mg} \mathrm{L}^{-1}$ yielded optimal linearity $\left(\mathrm{R}^{2}>0.9996\right)$. The quantification limit was $0.8 \mathrm{mg} \mathrm{L}^{-1}$.

The HPLC system used for the kinetic experiments and OFL adsorption at $10 \mu \mathrm{g} \mathrm{L}^{-1}$ consists of a pump Series 200 (Perkin Elmer, Milano, Italy) equipped with a vacuum degasser and a programmable fluorescence detector (FD). The fluorescence excitation/emission wavelengths selected were $280 / 500 \mathrm{~nm}$. Fifty $\mu \mathrm{L}$ of each sample were filtered $(0.22 \mu \mathrm{m})$ and injected into a $250 \times 4.6 \mathrm{~mm}, 5 \mu \mathrm{m}$ Ascentis RPAmide (Supelco-Merck Life Science, Milano, Italy) coupled with a similar guard-column. The mobile phase was $25 \mathrm{mM} \mathrm{H}_{3} \mathrm{PO}_{4}-\mathrm{ACN}$ (85:15), a flow rate of $1 \mathrm{~mL} \mathrm{~min}^{-1}$.

Calibration with four standards at concentrations between 1 and $10 \mu \mathrm{g} \mathrm{L}^{-1}$ yielded optimal linearity $\left(\mathrm{R}^{2}>0.9996\right)$. The quantification limit was $0.9 \mu \mathrm{g} \mathrm{L}-1$.

\section{Results and Discussion}

In the present work, two different zinc-based MOFs, ZIF- 8 and $\mathrm{Zn}_{3}(\mathrm{BTC})_{2}$, were critically compared to remove OFL antibiotic under relevant real conditions and characterized before and after their use.

\subsection{MOFs Characterization \\ 3.1.1. ZIF-8}

In Figure 1a, the X-ray powder diffraction pattern of the ZIF-8 sample is shown, compared to the one simulated on the basis of the crystal structure reported in the literature [33] and deposited in the Cambridge Crystallographic Data Centre (CCDC 864310). The diffraction patterns display comparable peak positions and intensities, suggesting that the crystalline ZIF-8 sample has been successfully synthesized. The crystalline structure is preserved after activation, as confirmed by the diffraction pattern shown in Figure 1a (pattern c).

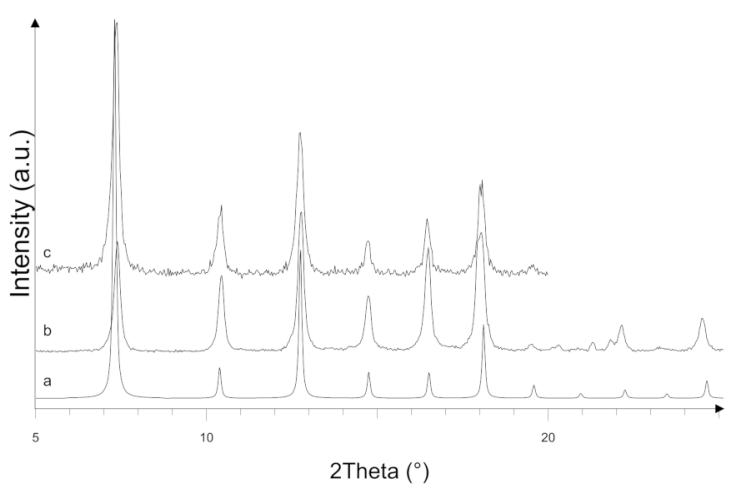

(a)

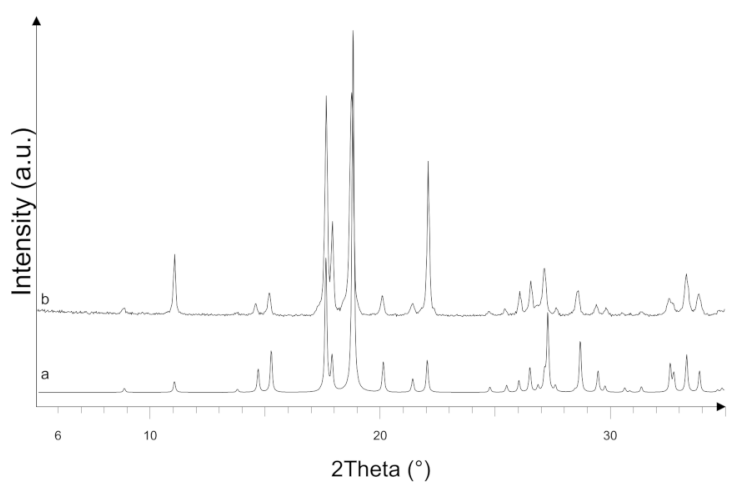

(b)

Figure 1. X-ray powder diffraction (XRPD) of (a) zeolitic imidazolate framework-8 (ZIF-8) and (b) Zn(II) and benzene-1,3,5tri-carboxylate $\left(\mathrm{Zn}_{3}(\mathrm{BTC})_{2}\right)$ : simulated (pattern a), as prepared (pattern b), and activated (pattern c). a.u. = arbitrary units

The FT-IR spectrum of the ZIF-8 sample is shown in Figure 2a. The observed bands are consistent with those reported in the literature for ZIF-8 [34-37]. The signals at 1673 
and $1565 \mathrm{~cm}^{-1}$ are attributed to the $\mathrm{C}=\mathrm{C}$ and $\mathrm{C}=\mathrm{N}$ stretch modes, respectively. The bands at $1300-1460 \mathrm{~cm}^{-1}$ are due to the ring stretching. The band at $1143 \mathrm{~cm}^{-1}$ and the peaks at 991 and $754 \mathrm{~cm}^{-1}$ are assigned to the stretching mode of the aromatic $\mathrm{C}-\mathrm{N}$ and to the $\mathrm{C}-\mathrm{N}$ bending vibration and $\mathrm{C}-\mathrm{H}$ bending modes, respectively. The band at $697 \mathrm{~cm}^{-1}$ is due to the ring out of plane bending vibration of the 2-methylimidazole. Figure 3a shows the SEM image of the ZIF-8 sample. Rounded particles with a homogeneous size of about $100 \mathrm{~nm}$ are observed. They are interconnected to form large agglomerates.

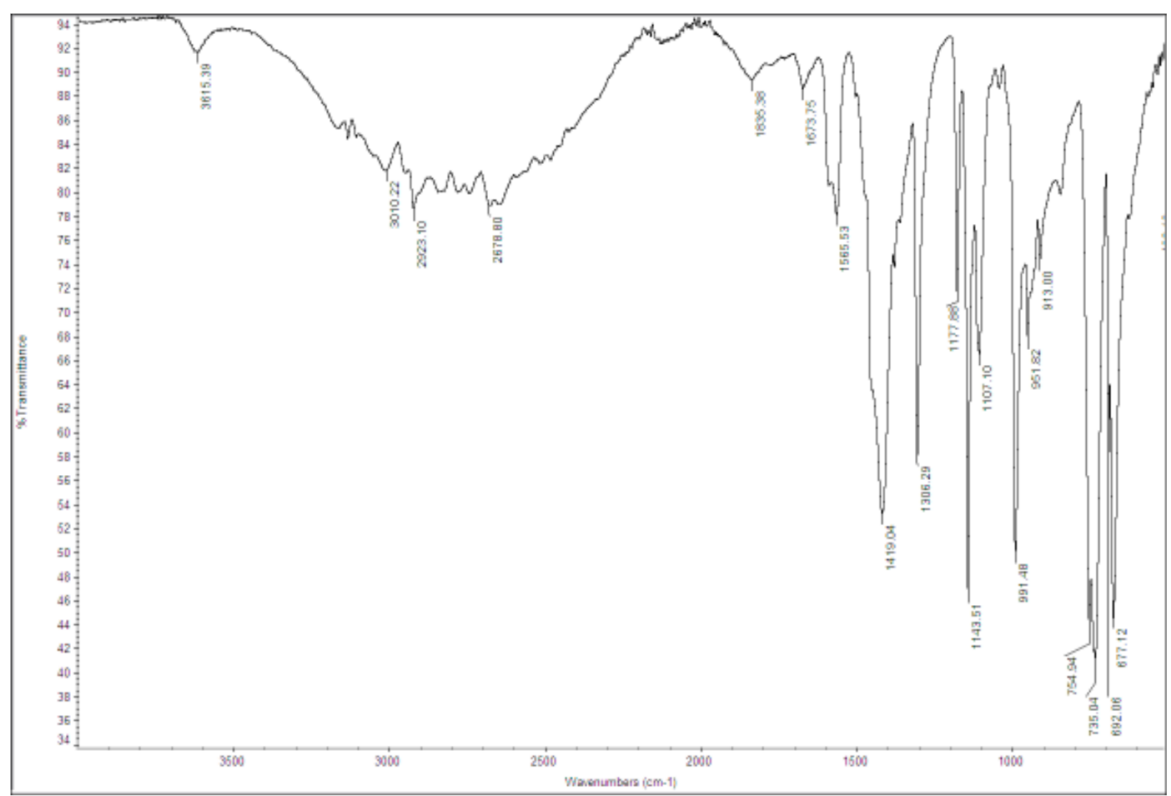

(a)

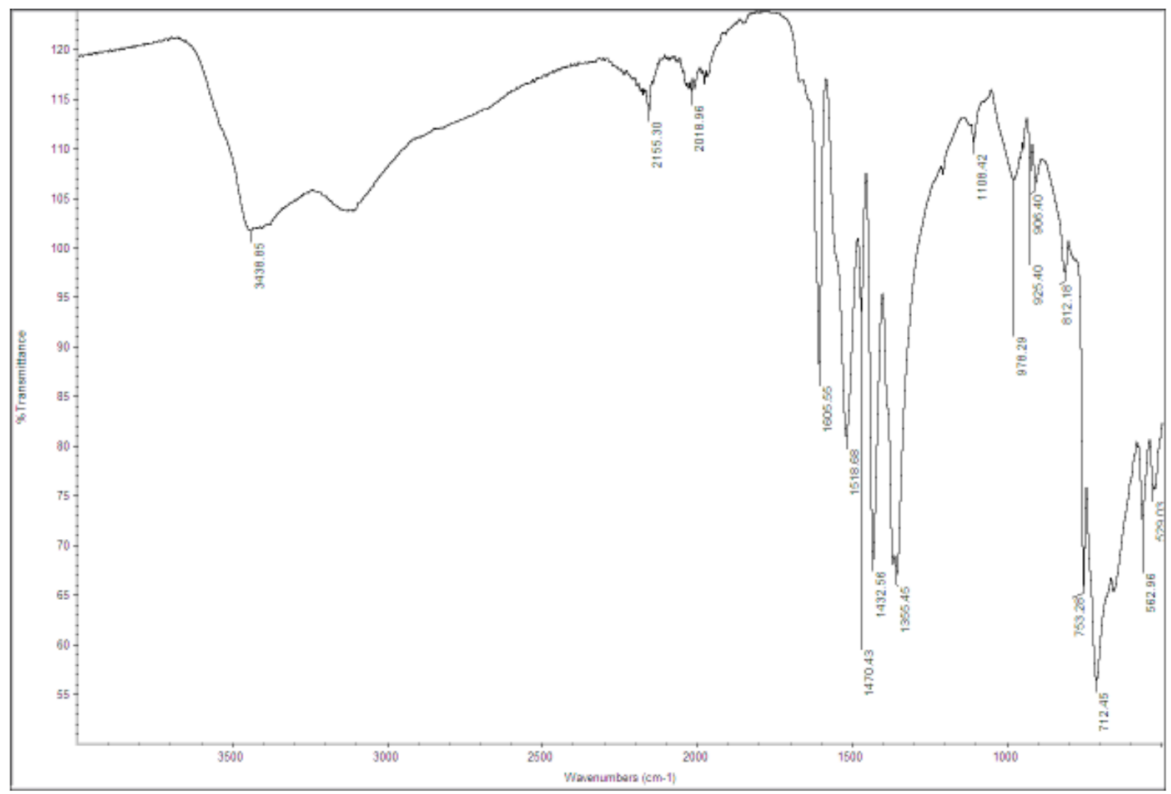

(b)

Figure 2. Fourier-Transform Infrared (FT-IR) spectra of (a) ZIF-8 and (b) $\mathrm{Zn}_{3}(\mathrm{BTC})_{2}$ samples. 


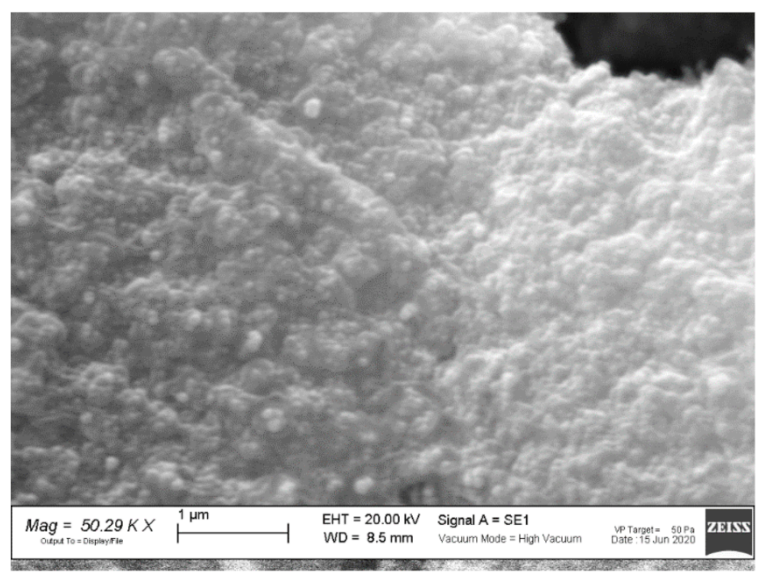

(a)

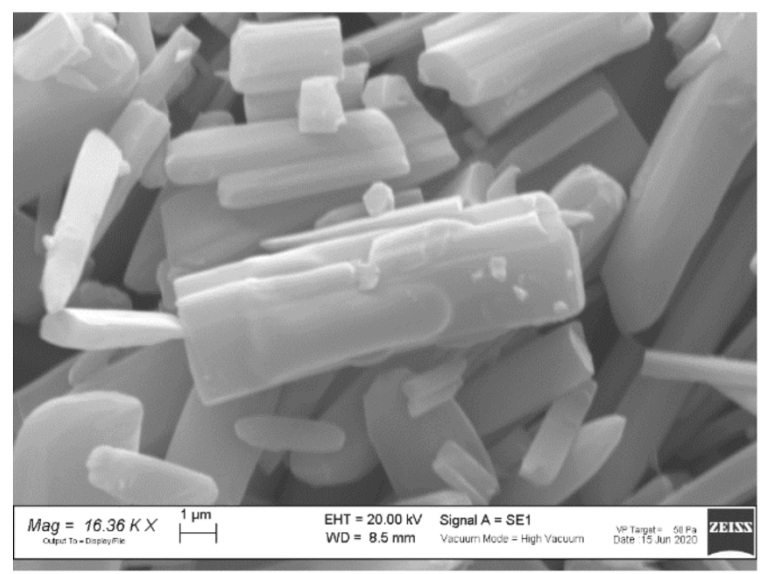

(b)

Figure 3. Scanning Electron Microscopy (SEM) images of (a) ZIF-8 and (b) $\mathrm{Zn}_{3}(\mathrm{BTC})_{2}$ samples.

\subsection{2. $\mathrm{Zn}_{3}(\mathrm{BTC})_{2}$}

The XRPD pattern of the $\mathrm{Zn}_{3}(\mathrm{BTC})_{2}$ sample is shown in Figure $1 \mathrm{~b}$ and compared to the simulated pattern obtained by the crystal structure reported in the literature [30] and deposited in the Cambridge Crystallographic Data Centre (CCDC-1274034). The diffraction patterns display comparable peak positions, suggesting that the crystalline $\mathrm{Zn}_{3}(\mathrm{BTC})_{2}$ sample has been successfully prepared.

The FT-IR spectrum of the $\mathrm{Zn}_{3}(\mathrm{BTC})_{2}$ sample is shown in Figure $2 \mathrm{~b}$. The signals are consistent with those reported in the literature for $\mathrm{Zn}_{3}(\mathrm{BTC})_{2}$ [29]. The broad peaks observed at $3300-2700 \mathrm{~cm}^{-1}$ and $3450 \mathrm{~cm}^{-1}$ are attributed to the stretching vibration of $\mathrm{O}-\mathrm{H}$ bonds of trimesic acid, indicating coordinated water molecules in the MOF. At $3438 \mathrm{~cm}^{-1}$, the $\mathrm{C}-\mathrm{H}$ aromatic bands are shown. The peak at $1518 \mathrm{~cm}^{-1}$ is attributed to the $\mathrm{C}=\mathrm{C}$ bond in the aromatic ring. More interestingly, the $-\mathrm{COOH}$ absorption bands typically observed at $1730-1690 \mathrm{~cm}^{-1}$ are not detected, thus demonstrating that the trimesic acid is bound to the metal center. The band detected at $753 \mathrm{~cm}^{-1}$ is assigned to the $\mathrm{Zn}-\mathrm{O}$ stretching vibration.

Figure $3 \mathrm{~b}$ shows the SEM image of the $\mathrm{Zn}_{3}(\mathrm{BTC})_{2}$ sample. It displays stick-like shaped particles with a smooth surface and irregular particle size: 2-10 $\mu \mathrm{m}$ in length, and $1-3 \mu \mathrm{m}$ thickness.

\subsection{Preliminary Experiments}

Since both $\mathrm{pH}$ and ionic strength affect the adsorption process $[17,20,24]$, a set of preliminary experiments were carried out to evaluate the feasibility of the adsorption process under real conditions. For this purpose, tap water was chosen as a solvent because of its invariant composition and a more remarkable similarity to environmental waters than the ultrapure one. In Appendix A, the physicochemical parameters of the municipal water collected in Pavia are shown.

First, working $\mathrm{pH}$ was evaluated. $10 \mathrm{mg}$ of $\mathrm{ZIF}-8$ and $\mathrm{Zn}_{3}(\mathrm{BTC})_{2}$ were separately suspended in $20 \mathrm{~mL}$ of tap water not containing the drug and shaken $(90 \mathrm{rpm})$ for $24 \mathrm{~h}$ at room temperature. Then the suspensions were centrifuged, and the supernatants separated for the $\mathrm{pH}$ measurement. The measured $\mathrm{pH}$ values were 9.0 and 6.7 , respectively.

No additional treatment was necessary for $\mathrm{Zn}_{3}(\mathrm{BTC})_{2}$ suspension, while small volumes of $1 \mathrm{M} \mathrm{HCl}$ were added to ZIF-8 suspension to adjust the $\mathrm{pH}$ in the range of 6.5-8.3, typical of environmental waters. Specifically, 8.1 and $6.7 \mathrm{pH}$ values were obtained, adding 50 and $100 \mu \mathrm{L}$ of $1 \mathrm{M} \mathrm{HCl}$, respectively.

Previous investigations regarding ZIF-8 thermal and chemical stabilities showed its exceptional hydrolysis resistance in benzene solution, methanol, water, and aqueous sodium hydroxide [26]. On the contrary, its application was limited by dissolution under 
acidic conditions $[38,39]$. For this reason, we decided to add the smallest $1 \mathrm{M} \mathrm{HCl}$ volume tested and work at $\mathrm{pH}$ around 8 .

A further test was carried out in parallel on activated and not activated ZIF-8 following the procedure reported in Section 2.4.1. Each material $(10 \mathrm{mg})$ was separately suspended in $9 \mathrm{mg} \mathrm{L}^{-1}$ OFL tap water solution. After $24 \mathrm{~h}$ equilibration, the drug percentage uptake resulted in 76 and $38 \%$, respectively. Consequently, all experiments were carried out on the activated form.

On the contrary, $\mathrm{Zn}_{3}(\mathrm{BTC})_{2}$ was used without activation to avoid any loss of crystallinity, as demonstrated by XRPD data collected on a sample activated at $80{ }^{\circ} \mathrm{C}$ (data not shown).

Based on the recent literature regarding drug adsorption on MOFs [16,17,19,22], $10 \mathrm{mg}$ of MOF was chosen for all the experiments. Yu and Wu [20] observed a decreased OFL adsorption capacity increasing ZIF-8 amount from 10 to $50 \mathrm{mg}$.

\subsection{Isotherm and Kinetic Studies}

\subsubsection{Isotherm Studies}

Adsorption isotherms are widely used to characterize the retention of chemicals in a solid phase, describing the maximum uptake and the relationship between the amount of the adsorbed molecule $\left(q_{e}\right)$ and the dissolved molecule's concentration $\left(C_{e}\right)$ in the solution at equilibrium quantitatively.

In this paper, the most frequently used models, i.e., Freundlich and Langmuir, and the sigmoidal and Brunauer-Emmett-Teller (BET) models, were applied to better describe OFL adsorption onto $\mathrm{ZIF}-8$ and $\mathrm{Zn}_{3}(\mathrm{BTC})_{2}$.

The Freundlich model, usually applied to non-ideal adsorption on the heterogeneous surface, is expressed by the following Equation (3):

$$
q_{e}=K_{F} C_{e}^{1 / n}
$$

where $K_{F}$ is the empirical constant indicative of adsorption capacity, and $n$ is the empirical parameter representing the heterogeneity of site energies.

The Langmuir model (Equation (4)) assumes that the adsorption process occurs in a monolayer that covers the surface of the material:

$$
q_{e}=\frac{q_{m} K_{L} C_{e}}{1+K_{L} C_{e}}
$$

where $K_{L}$ is the Langmuir constant and $q_{m}$ the monolayer saturation capacity.

The sigmoidal model (Equation (5)) usually describes cooperative adsorption, and it is expressed by the equation:

$$
q_{e}=\frac{q_{m}}{1+e^{-A\left(C_{e}-F\right)}}
$$

where $q_{m}$ is the maximum amount of molecules adsorbed, $A$ is a coefficient indicating the adsorption mechanism's efficiency, and $F$ represents the inflection point.

BET isotherm for liquid-phase adsorption (Equation (6)) was applied [40] to evaluate the adsorption equilibrium constant of potential upper layers $\left(K_{L}\right)$ along with the equilibrium constant for the first layer $\left(K_{S}\right)$ :

$$
q_{e}=q_{m} \frac{K_{s} C_{e q}}{\left(1-K_{L}\right)\left(1-K_{L} C_{e q}+K_{s} C_{e q}\right)}
$$

As shown in Figure 4a,b, the experimental adsorption profiles of OFL on ZIF-8 and $\mathrm{Zn}_{3}(\mathrm{BTC})_{2}$ are quite different, as well as their maximum uptake, $95 \pm 10 \mathrm{mg} \mathrm{g}^{-1}$ for ZIF-8 and $25.3 \pm 0.8 \mathrm{mg} \mathrm{g}^{-1}$ for $\mathrm{Zn}_{3}(\mathrm{BTC})_{2}$. 


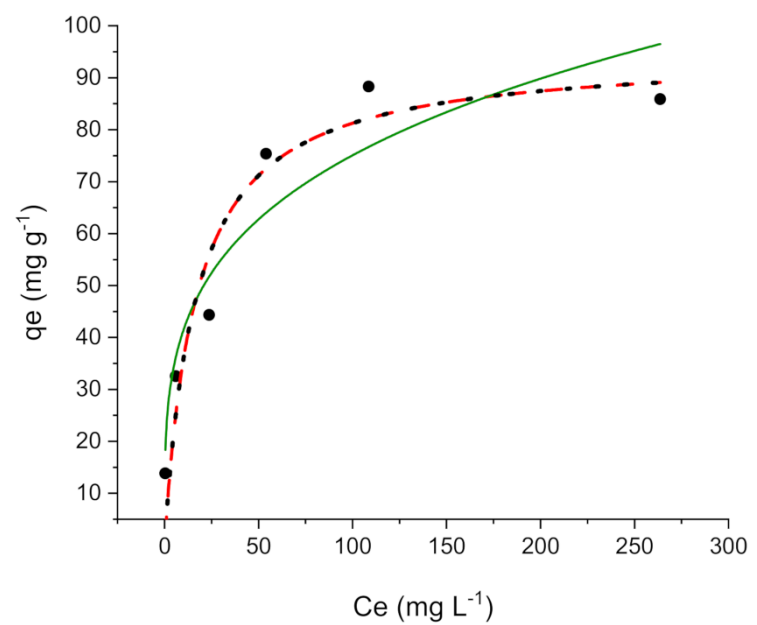

(a)

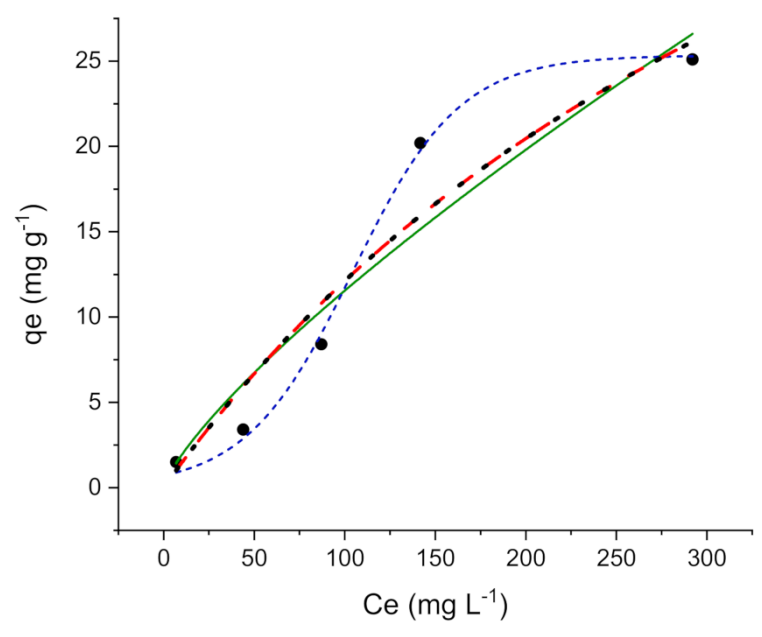

(b)

Figure 4. Adsorption profiles Langmuir (--), Freundlich (-), Brunauer-Emmett-Teller BET (.......), and sigmoidal (-.-) for Ofloxacin (OFL) on (a) ZIF-8 and (b) $\mathrm{Zn}_{3}(\mathrm{BTC})_{2}$. (Experimental conditions: MOF (metal-organic framework) $10 \mathrm{mg}, 20 \mathrm{~mL}$ OFL solution from 8 to $\left.305 \mathrm{mg} \mathrm{L}^{-1}\right)$.

OFL adsorption took place on ZIF-8 clearly at specific homogeneous sites within the adsorbent, while a sigmoidal profile was observed for $\mathrm{Zn}_{3}(\mathrm{BTC})_{2}$. Table 1.

The isotherm parameters were calculated by dedicated software and are listed in

Table 1. Isotherm parameters were obtained by fitting the experimental data for OFL adsorption onto ZIF-8 and $\mathrm{Zn}_{3}(\mathrm{BTC})_{2}$.

\begin{tabular}{cccc}
\hline Adsorption Model & Isotherm Parameters & ZIF-8 & Zn $_{\mathbf{3}}(\mathbf{B T C})_{\mathbf{2}}$ \\
\hline \multirow{3}{*}{ Freundlich } & $q_{m \exp }\left(\mathrm{mg} \mathrm{g}^{-1}\right)$ & $88 \pm 3$ & $25 \pm 3$ \\
& $K_{F}\left(\mathrm{mg}^{(1-n)} \mathrm{L}^{n} \mathrm{~g}^{-1}\right)$ & $23 \pm 6$ & $0.002 \pm 0.002$ \\
& $1 / n\left(\mathrm{~g} \mathrm{~min}^{-1} \mathrm{mg}^{-1}\right)$ & $0.26 \pm 0.06$ & $0.8 \pm 0.2$ \\
Langmuir & $\mathrm{R}^{2}$ & 0.879 & 0.881 \\
& $K_{L}\left(\mathrm{~L} \mathrm{mg}^{-1}\right)$ & $0.06 \pm 0.03$ & $0.002 \pm 0.002$ \\
& $q_{m}\left(\mathrm{mg} \mathrm{g}^{-1}\right)$ & $95 \pm 10$ & $66 \pm 45$ \\
BET & $\mathrm{R}^{2}$ & 0.902 & 0.903 \\
& $K_{s}\left(\mathrm{~L} \mathrm{mg}^{-1}\right)$ & $0.06 \pm 0.03$ & $0.002 \pm 0.003$ \\
& $K_{L}\left(\mathrm{~L} \mathrm{mg}^{-1}\right)$ & $7.2 \times 10^{-22} \pm 0$ & $2.1 \times 10^{-19} \pm 0$ \\
& $q_{m}\left(\mathrm{mg} \mathrm{g}^{-1}\right)$ & $95 \pm 11$ & $65 \pm 55$ \\
$\mathrm{R}^{2}$ & 0.869 & 0.855 \\
\hline \multirow{2}{*}{ Sigmoidal } & $A$ & - & $0.034 \pm 0.003$ \\
& $F$ & - & $104 \pm 4$ \\
& $q_{m}\left(\mathrm{mg} \mathrm{g}^{-1}\right)$ & - & $25.3 \pm 0.8$ \\
$\mathrm{R}^{2}$ & - & 0.994 \\
\hline
\end{tabular}

OFL: Ofloxacin; BET: Brunauer-Emmett-Teller ZIF-8: zeolitic imidazolate framework-8; $\mathrm{Zn}_{3}(\mathrm{BTC})_{2}$ : Zn(II) and benzene-1,3,5-tri-carboxylate; $q_{m}$ : monolayer saturation capacity; $K_{F}$ : empirical constant indicative of adsorption capacity; $K_{L}$ : Langmuir constant; $K_{s}$ : equilibrium constant for the first layer; $A$ : sigmoidal efficiency adsorption constant; $F$ : sigmoidal flex.

For ZIF-8, the correlation coefficient $\left(\mathrm{R}^{2}\right)$ and the lower standard deviations of Langmuir parameters confirm that the drug adsorption occurred through a monolayer coverage. $K_{S}(0.06 \pm 0.03)$ and $q_{m}$ values obtained by applying the BET model confirmed the monolayer adsorption process, and the $K_{L}$ value indicated that no multi-layer adsorption occurred. 
The profile observed for $\mathrm{Zn}_{3}(\mathrm{BTC})_{2}$ describes cooperative adsorption and indicates that at lower OFL concentration in the solution, the adsorption is low, increasing when the solute concentration increases. A similar trend was found in previous studies regarding the adsorption of organic molecules onto various adsorbent materials [8-10,41].

The experimental OFL equilibrium uptake $\left(q_{m \text { exp }}\right)$ is in good agreement with the calculated one for both the investigated materials, as shown in Table 1. Both ZIF-8 and $\mathrm{Zn}_{3}(\mathrm{BTC})_{2}$ have a good affinity towards OFL and are competitive in term of adsorption capacity compared with other MOFs used for the same purpose. For example, the adsorption capacities ranges from $50 \mathrm{mg} \mathrm{g}^{-1}$ for UiO-66- $\mathrm{NH}_{2} @ \mathrm{RAMIP@BSA} \mathrm{to} 133 \mathrm{mg} \mathrm{g}^{-1}$ for $\mathrm{UiO}-67 / \mathrm{CdS} / \mathrm{rGO}-\mathrm{x}[42,43]$.

\subsubsection{Kinetic Studies}

Various adsorption kinetic mechanistic models were used to describe OFL uptake on the two investigated MOFs, i.e., the most common pseudo-first-order (Equation (7)) and the pseudo-second-order (Equation (8)) equations, and a sigmoidal one (Equation (9)).

$$
\begin{gathered}
q_{t}=q_{e}\left(1-e^{-k_{1} t}\right) \\
q_{t}=\frac{\left(q_{e}^{2} k_{2} t\right)}{\left(1+q_{e} k_{2} t\right)} \\
q_{t}=\frac{q_{e}}{1+e^{-A\left(C_{t}-F\right)}}
\end{gathered}
$$

where $q_{t}$ and $q_{e}$ were the OFL amount adsorbed at time $t$ and at equilibrium, respectively, $k_{1}$ was the pseudo-first order rate constant, $k_{2}$ the pseudo-second-order rate constant, $A$ the sigmoidal efficiency adsorption constant, $F$ the sigmoidal flex.

The experimental kinetic profiles are shown in Figure $5 a, b$ and revealed a different trend under the same experimental conditions.

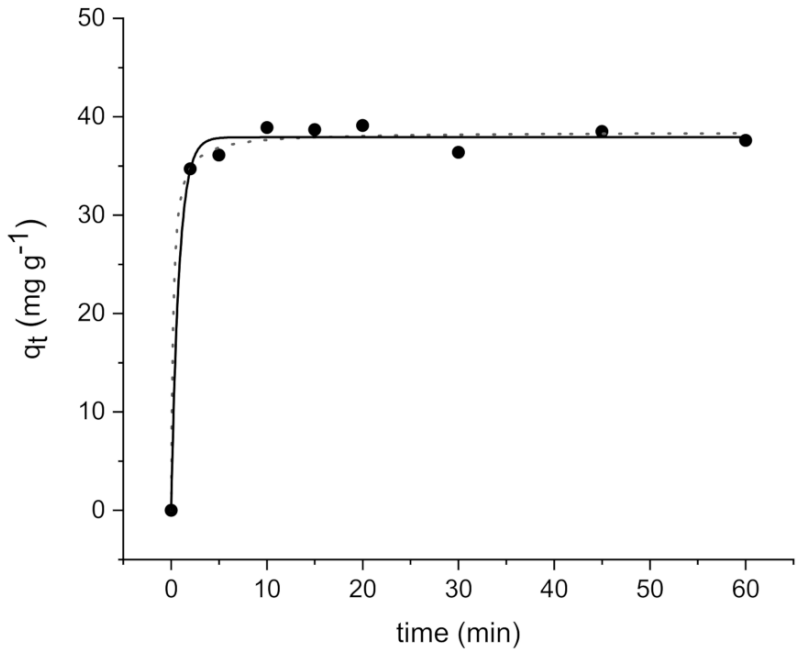

(a)

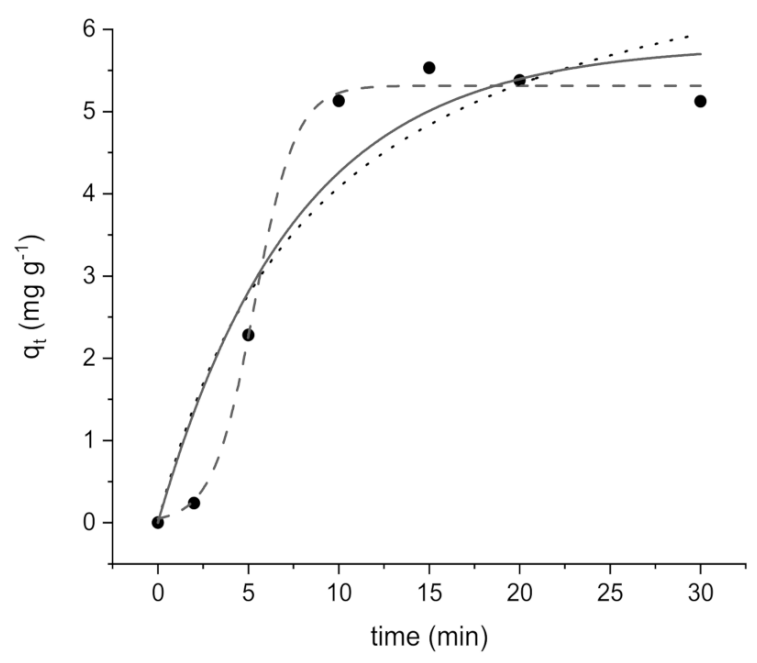

(b)

Figure 5. Kinetic profiles (pseudo-first-order (_), pseudo-second order (....), and sigmoidal (...)) for Ofloxacin (OFL) on (a) ZIF-8 (Experimental conditions: metal-organic frameworks (MOF) $20 \mathrm{mg}$, $40 \mathrm{~mL}$ tap water, OFL initial concentration $36 \mathrm{mg} \mathrm{L}^{-1}$ ) and (b) $\mathrm{Zn}_{3}(\mathrm{BTC})_{2}$ (Experimental conditions: MOF $20 \mathrm{mg}, 40 \mathrm{~mL}$ tap water, OFL initial concentration $12 \mathrm{mg} \mathrm{L}^{-1}$ ).

The kinetic parameters obtained by fitting the experimental data are shown in Table 2.

Being the correlation coefficient $\left(\mathrm{R}^{2}\right)$ for ZIF-8 always higher than 0.99 , both Equations (7) and (8) models should describe the kinetics of the process. However, the pseudo-second-order model seems to fit the experimental data better than the pseudo-firstorder, as shown in Figure 5a and reported by other authors [20]. 
Table 2. Kinetic parameters were obtained by fitting the experimental data for OFL adsorption on ZIF-8 and $\mathrm{Zn}_{3}(\mathrm{BTC})_{2}$.

\begin{tabular}{|c|c|c|c|}
\hline Kinetic Model & Kinetic Parameters & ZIF-8 & $\mathrm{Zn}_{3}(\mathrm{BTC})_{2}$ \\
\hline & $q_{e \exp }\left(\mathrm{mg} \mathrm{g}^{-1}\right)$ & $37.6 \pm 2$ & $4.9 \pm 2$ \\
\hline \multirow{3}{*}{ Pseudo-first order } & $k_{1}\left(\min ^{-1}\right)$ & $1.2 \pm 0.2$ & $0.13 \pm 0.05$ \\
\hline & $\mathrm{R}^{2}$ & 0.992 & 0.907 \\
\hline & $q_{e}\left(\mathrm{mg} \mathrm{g}^{-1}\right)$ & $37.9 \pm 0.4$ & $5.8 \pm 0.7$ \\
\hline \multirow{3}{*}{ Pseudo-second order } & $k_{2}\left(\mathrm{~g} \mathrm{mg}^{-1} \mathrm{~min}^{-1}\right)$ & $0.12 \pm 0.04$ & $0.01 \pm 0.01$ \\
\hline & $\mathrm{R}^{2}$ & 0.993 & 0.896 \\
\hline & $q_{e}\left(\mathrm{mg} \mathrm{g}^{-1}\right)$ & $38.4 \pm 0.5$ & $8 \pm 2$ \\
\hline \multirow{4}{*}{ Sigmoidal } & $A$ & - & $0.9 \pm 0.2$ \\
\hline & $F$ & - & $5.3 \pm 0.2$ \\
\hline & $\mathrm{R}^{2}$ & - & 0.997 \\
\hline & $q_{e}\left(\mathrm{mg} \mathrm{g}^{-1}\right)$ & - & $5.31 \pm 0.08$ \\
\hline
\end{tabular}

On the contrary, in the case of $\mathrm{Zn}_{3}(\mathrm{BTC})_{2}$, the same kinetic models did not depict the experimental data, while the sigmoidal equation (Equation (9)) well fits the experimental data. A good $R^{2}$ was obtained.

According to these assessments, we can conclude that a fast uptake, lower than $10 \mathrm{~min}$, occurs on both the studied MOFs.

\subsection{Reusability and Post-Use Characterization of MOFs}

\subsubsection{Reusability}

After the first adsorption, both MOFs were separated and suspended for a second time in $20 \mathrm{~mL}$ tap water samples containing OFL $10 \mathrm{mg} \mathrm{L}^{-1}$, following the same procedure described for the adsorption isotherms (see Section 2.4.1). After $24 \mathrm{~h}$ equilibration, a negligible amount of antibiotic ( $<\mathrm{LOQ}$, Limit of Quantification) was adsorbed in both cases. Similar results were obtained after heating MOFs at $60^{\circ} \mathrm{C}$ after the first adsorption cycle and before the second one.

To evaluate the reasons limiting the MOFs' re-use, as demonstrated by the adsorption tests after the first use, both ZIF- 8 and $\mathrm{Zn}_{3}(\mathrm{BTC})_{2}$ have been characterized after OFL adsorption.

\subsubsection{ZIF-8/Ofloxacin System}

The ZIF-8 powder after the first OFL adsorption at $\mathrm{pH} 8.1$ was recovered by centrifugation and dried. The diffraction pattern is shown in Figure 6 and compared to the as-synthesized one. In the sample after the antibiotic adsorption, new peaks are detected. The obtained results suggest that ZIF-8 underwent a degradation. The decomposition process is not complete, as weak peaks pertinent to the ZIF- 8 are again observed in the pattern $b$.

The observation is also supported by FT-IR and SEM results. The FT-IR spectrum of the post-use ZIF-8 is shown in Figure 7; some additional bands in the $1400-1300 \mathrm{~cm}^{-1}$ region are observed, suggesting a degradation process occurred in the ZIF-8/OFL system. The spectrum of the as-synthesized ZIF-8 is also reported.

The SEM images of the ZIF-8 sample as-synthesized and after OFL adsorption at $\mathrm{pH}$ 8.1 are shown in Figure 8. Significant changes in particle morphology are detected after $\mathrm{MOF}$ is used. In particular, micrometric grains displaying flat surfaces are observed. The changes in morphology do not prove, but may be a consequence of, the occurrence of decomposition processes. 


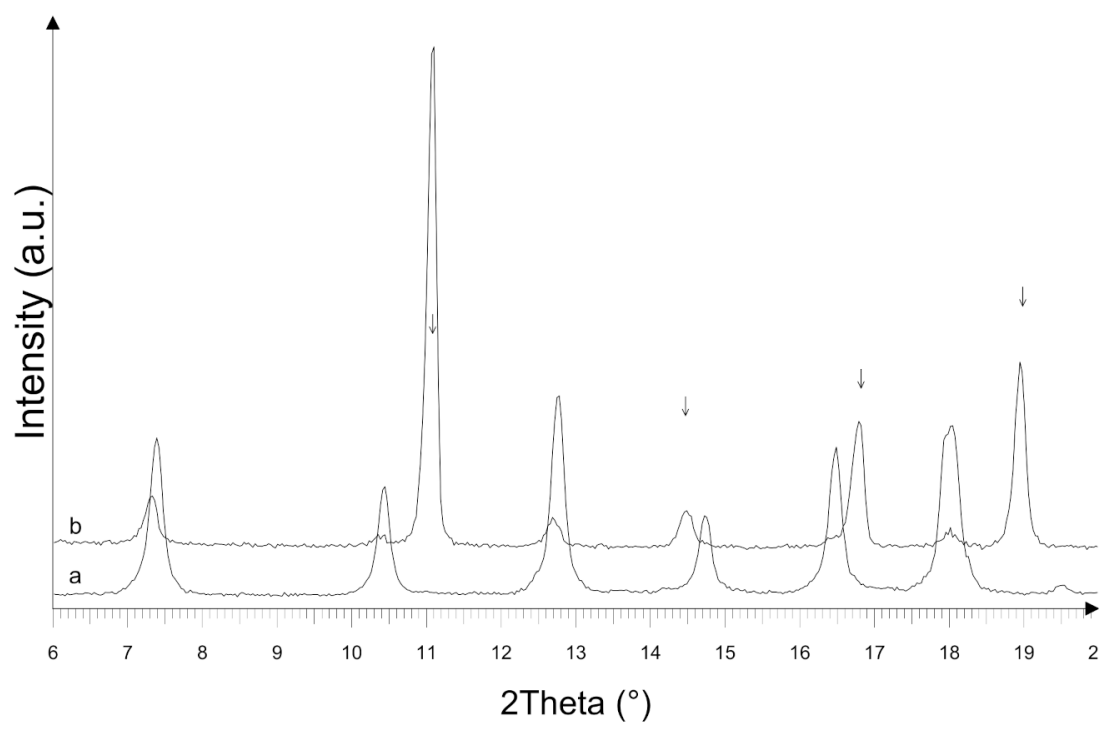

Figure 6. XRPD patterns of ZIF-8: As prepared (pattern a), after OFL adsorption at pH 8.1 (pattern b). The new peaks are indicated by arrows.

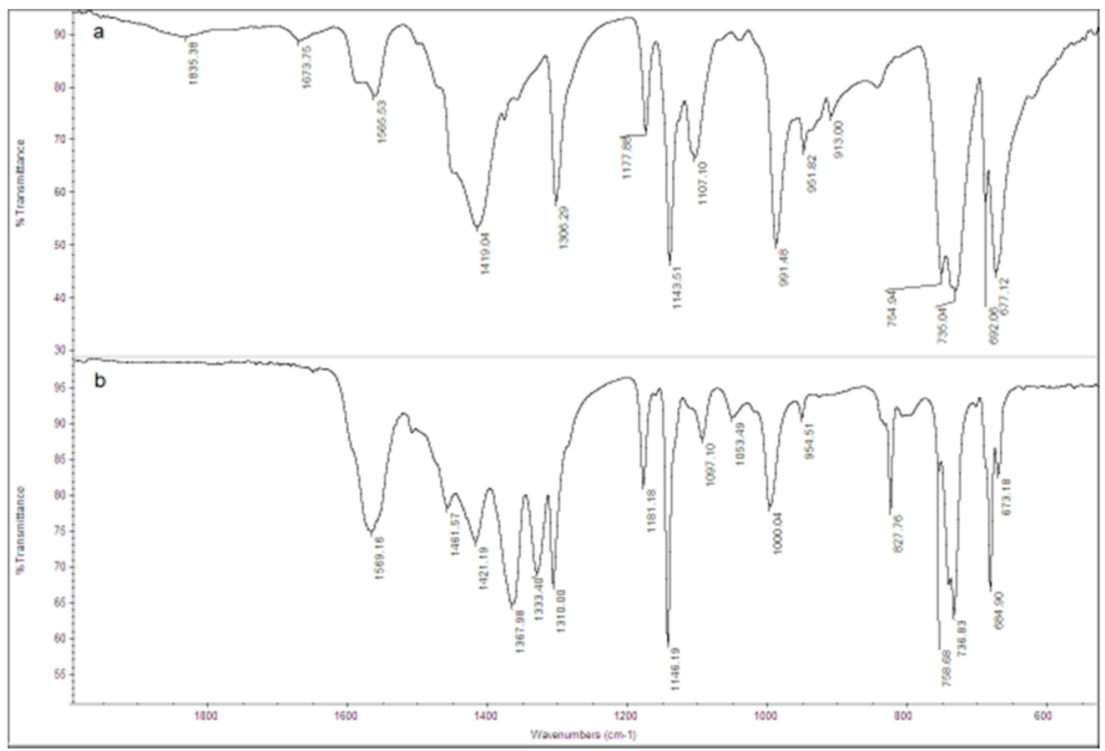

Figure 7. FT-IR spectra of ZIF-8: As-synthesized (spectrum a) and after OFL adsorption at pH 8.1 (spectrum b).

The degradation of the ZIF-8 structure after OFL adsorption at $\mathrm{pH} 8.1$ limits its possible re-use. This agrees with the literature reporting the ZIF-8 instability by decreasing the $\mathrm{pH}[26,38,39]$ and with our results: We demonstrated by XRPD technique that a ZIF-8 soaked in an acidic environment ( $\mathrm{pH}$ 6.7) completely decomposed (data not shown).

\subsection{3. $\mathrm{Zn}_{3}(\mathrm{BTC})_{2} /$ Ofloxacin System}

Figure 9 shows the $\mathrm{Zn}_{3}(\mathrm{BTC})_{2}$ diffraction pattern after OFL adsorption in tap water. The as-synthesized $\mathrm{Zn}_{3}(\mathrm{BTC})_{2}$ pattern is also shown for comparison. The $\mathrm{Zn}_{3}(\mathrm{BTC})_{2}$ diffraction peaks are not observed in the sample after use, while new broad peaks are detected, indicating the sample underwent amorphization and degradation. 


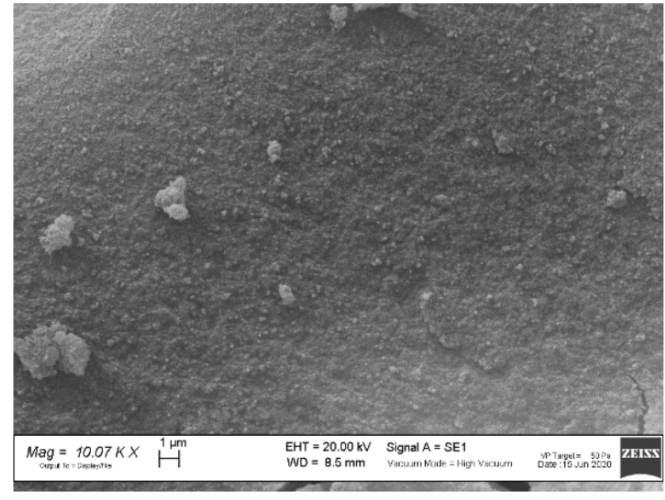

(a)

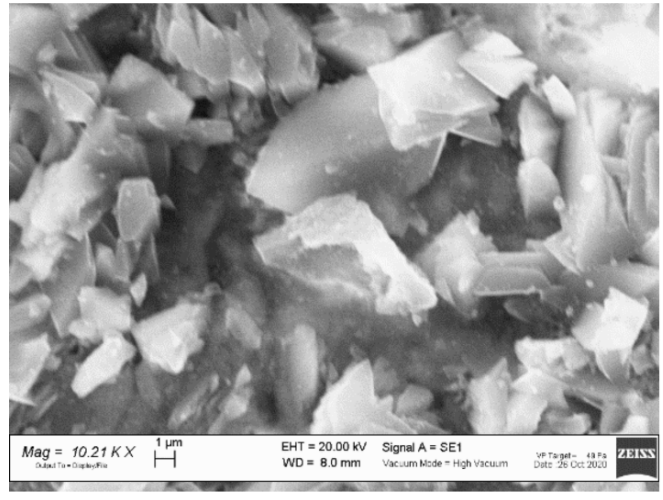

(b)

Figure 8. SEM images of the ZIF-8 samples: (a) As-synthesized and (b) after OFL adsorption at pH 8.1.

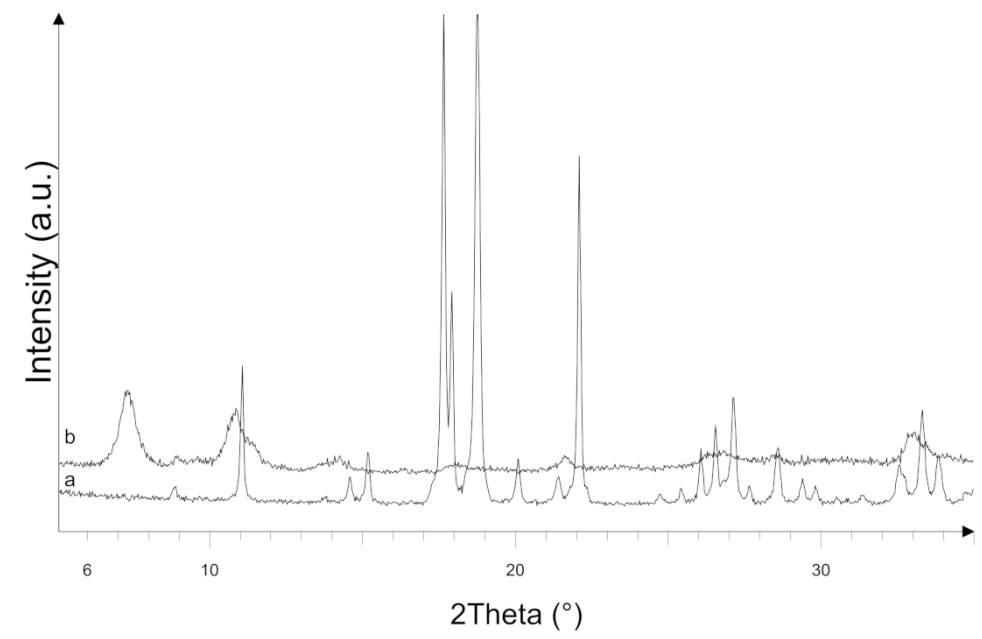

Figure 9. XRPD patterns of $\mathrm{Zn}_{3}(\mathrm{BTC})_{2}$ : As-synthesized (pattern a) and after OFL adsorption in tap water (pattern b).

Figure 10 shows the FT-IR spectra of $\mathrm{Zn}_{3}(\mathrm{BTC})_{2}$ as-synthesized and after OFL adsorption. Some changes are observed in the $1700-1300 \mathrm{~cm}^{-1}$ spectral region after use, confirming the degradation process occurred.

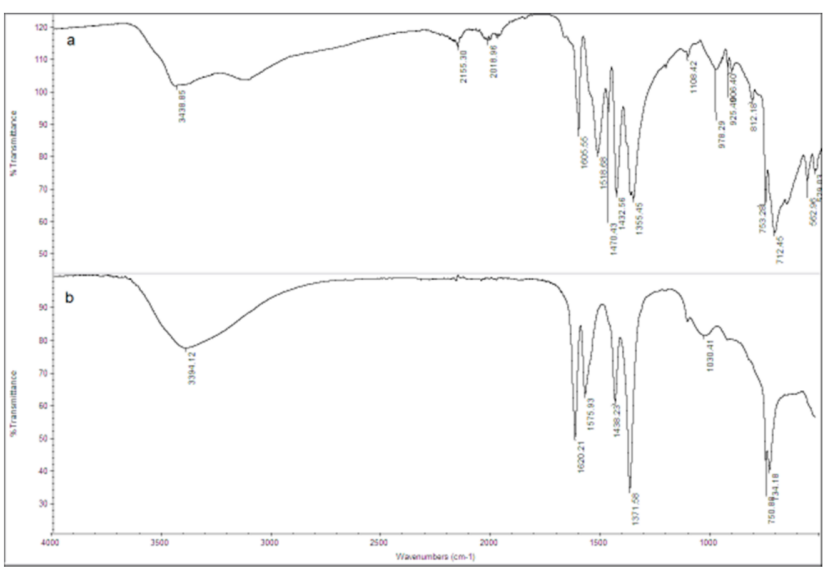

Figure 10. FT-IR spectra of $\mathrm{Zn}_{3}(\mathrm{BTC})_{2}$ : As prepared (spectrum a) and after OFL adsorption in tap water (spectrum b). 
The SEM image of the $\mathrm{Zn}_{3}(\mathrm{BTC})_{2}$ after OFL adsorption in tap water is shown in Figure 11. An impressive change in particle morphology and grain size is detected after $\mathrm{Zn}_{3}(\mathrm{BTC})_{2}$ use (see Figure $3 \mathrm{~b}$, as-prepared sample); this evidence supports the loss of crystallinity and MOF degradation evidenced by XRPD and FT-IR results.

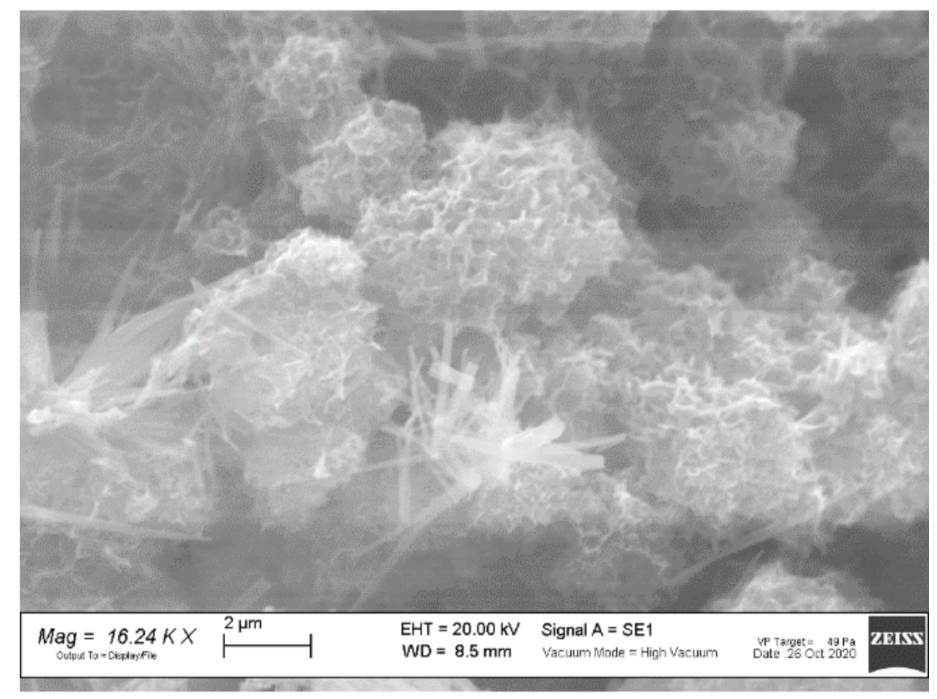

Figure 11. SEM image of the $\mathrm{Zn}_{3}(\mathrm{BTC})_{2}$ sample after OFL adsorption in tap water.

\section{Ofloxacin Adsorption at $10 \mu \mathrm{g} \mathrm{L}^{-1}$ Concentration}

The suitability of ZIF-8 and $\mathrm{Zn}_{3}(\mathrm{BTC})_{2}$ for OFL removal at a few $\mu \mathrm{g}$ per liter concentrations from contaminated water was investigated.

Each MOF (10 mg) was separately added to $20 \mathrm{~mL}$ tap water samples spiked with OFL $10 \mu \mathrm{g} \mathrm{L}^{-1}\left(C_{0}\right)$ and stirred overnight. Then, the supernatants were centrifuged and analyzed by HPLC-FD to determine the drug content $\left(C_{t}\right)$.

The removal efficiency $(r)$ was calculated via Equation (10):

$$
r=\frac{\left(C_{0}-C_{t}\right)}{C_{0}} \times 100
$$

where $C_{0}$ is the initial OFL concentration and $C_{t}$ the OFL concentration after a contact time $t$.

The obtained removal efficiencies were 88 (3) and 72 (3) \% for ZIF-8 and $\mathrm{Zn}_{3}(\mathrm{BTC})_{2}$, respectively. The results underline good antibiotic recoveries with such a small amount of adsorbent and in the presence of matrix constituents. The reusability disadvantage is then negligible, considering the reported advantages.

\section{Conclusions}

In this work, the adsorption properties of two different zinc-based metal-organic frameworks were explored to remove one of the most used fluoroquinolone antibiotic, Ofloxacin (OFL), from polluted water. The experimental results, presented and discussed herein, showed that both ZIF- 8 and $\mathrm{Zn}_{3}(\mathrm{BTC})_{2}$ have a good affinity towards OFL; nevertheless, different mechanisms were involved. Langmuir and sigmoidal models were found to describe better the isotherms adsorption, while pseudo-second-order and sigmoidal models are more suitable to describe the overall kinetic process, respectively. The equilibrium was reached in less than ten minutes for both materials.

Based on XRPD, FT-IR, and SEM analyses, a full investigation allowed us to find the reasons limiting the MOFs re-use. After adsorption in tap water, enhanced degradation of the ZIF 8 structure occurred, while $\mathrm{Zn}_{3}(\mathrm{BTC})_{2}$ degraded completely. This disadvantage is overshadowed by the satisfactory results obtained in terms of OFL removal efficiency, as 
high as 88 and $72 \%$ for $\mathrm{ZIF-} 8$ and $\mathrm{Zn}_{3}(\mathrm{BTC})_{2}$, respectively, under relevant real conditions, and by the small adsorbent amount used.

Summing up, the obtained results make these materials excellent candidates for removing FQs from contaminated waters.

Author Contributions: Conceptualization, D.C., M.S. and F.M. (Francesco Monteforte); formal analysis, G.G., C.P. and F.M. (Federica Maraschi); investigation, G.G., C.P., G.B. and F.M. (Francesco Monteforte); resources, A.P. and D.C.; writing — original draft preparation, M.S. and D.C.; writingreview and editing, D.C., M.S., G.G., C.P. and F.M. (Federica Maraschi); visualization, G.G. and C.P. All authors have read and agreed to the published version of the manuscript.

Funding: This research received no external funding.

Institutional Review Board Statement: Not applicable.

Informed Consent Statement: Not applicable.

Data Availability Statement: The data presented in this study are available on request from the corresponding author.

Acknowledgments: The authors are grateful to Filippo Groppi for the contribution he gave during his graduation thesis.

Conflicts of Interest: The authors declare no conflict of interest.

\section{Appendix A}

Table A1. Physico-chemical characterization of tap water sample

\begin{tabular}{|c|c|c|}
\hline Parameters/Ions & & Tap Water \\
\hline $\mathrm{pH}$ & & 7.7 \\
\hline Conductivity at $20^{\circ} \mathrm{C}$ & $\mu S \mathrm{~cm}^{-1}$ & 271 \\
\hline TOC & $\mathrm{mg} \mathrm{L}^{-1}$ & 4.2 \\
\hline $\mathrm{Cl}^{-}$ & $\mathrm{mg} \mathrm{L}^{-1}$ & 5.0 \\
\hline $\mathrm{NO}_{3}^{-}$ & $\mathrm{mg} \mathrm{L}^{-1}$ & 0.6 \\
\hline $\mathrm{SO}_{4}{ }^{2-}$ & $\mathrm{mg} \mathrm{L}^{-1}$ & 5.0 \\
\hline $\mathrm{HCO}_{3}{ }^{-}$ & $\mathrm{mg} \mathrm{L}^{-1}$ & 182 \\
\hline $\mathrm{Ca}^{2+}$ & $\mathrm{mg} \mathrm{L}^{-1}$ & 35 \\
\hline $\mathrm{Mg}^{2+}$ & $\mathrm{mg} \mathrm{L}^{-1}$ & 10 \\
\hline $\mathrm{Na}^{+}$ & $\mathrm{mg} \mathrm{L}^{-1}$ & 12 \\
\hline
\end{tabular}

\section{References}

1. European Commission. 2019 Communication from the Commission to the European Parliament, the Council, and the European Economic and Social Committee: European Union Strategic Approach to Pharmaceuticals in the Environment. Com (2019) 2019, $128,13$.

2. Sousa, J.C.G.; Ribeiro, A.R.; Barbosa, M.O.; Pereira, M.F.R.; Silva, A.M.T. A review on environmental monitoring of water organic pollutants identified by EU guidelines. J. Hazard. Mater. 2018, 344, 146-162. [CrossRef] [PubMed]

3. Biancullo, F.; Moreira, N.F.F.; Ribeiro, A.R.; Manaia, C.M.; Faria, J.L.; Nunes, O.C.; Castro-Silva, S.M.; Silva, A.M.T. Heterogeneous photocatalysis using UVA-LEDs for the removal of antibiotics and antibiotic resistant bacteria from urban wastewater treatment plant effluents. Chem. Eng. J. 2019, 367, 304-313. [CrossRef]

4. Castiglioni, S.; Davoli, E.; Riva, F.; Palmiotto, M.; Camporini, P.; Manenti, A.; Zuccato, E. Data on occurrence and fate of emerging contaminants in a urbanised area. Data Br. 2018, 17, 533-543. [CrossRef]

5. Riva, F.; Castiglioni, S.; Fattore, E.; Manenti, A.; Davoli, E.; Zuccato, E. Monitoring emerging contaminants in the drinking water of Milan and assessment of the human risk. Int. J. Hyg. Environ. Health 2018, 221, 451-457. [CrossRef]

6. Merlin, C. Reducing the Consumption of Antibiotics: Would That Be Enough to Slow Down the Dissemination of Resistances in the Downstream Environment? Front. Microbiol. 2020, 11, 33. [CrossRef]

7. Sophia A., C.; Lima, E.C. Removal of emerging contaminants from the environment by adsorption. Ecotoxicol. Environ. Saf. 2018, 150,1-17. [CrossRef] 
8. Maraschi, F.; Sturini, M.; Speltini, A.; Pretali, L.; Profumo, A.; Pastorello, A.; Kumar, V.; Ferretti, M.; Caratto, V. TiO 2 -modified zeolites for fluoroquinolones removal from wastewaters and re-use after solar light regeneration. J. Environ. Chem. Eng. 2014, 2, 2170-2176. [CrossRef]

9. Sturini, M.; Speltini, A.; Maraschi, F.; Profumo, A.; Tarantino, S.; Gualtieri, A.F.; Zema, M. Removal of fluoroquinolone contaminants from environmental waters on sepiolite and its photo-induced regeneration. Chemosphere 2016, 150, 686-693. [CrossRef]

10. Rivagli, E.; Pastorello, A.; Sturini, M.; Maraschi, F.; Speltini, A.; Zampori, L.; Setti, M.; Malavasi, L.; Profumo, A. Clay minerals for adsorption of veterinary FQs: Behavior and modeling. J. Environ. Chem. Eng. 2014, 2, 738-744. [CrossRef]

11. Gao, Q.; Xu, J.; Bu, X.-H. Recent advances about metal-organic frameworks in the removal of pollutants from wastewater. Coord. Chem. Rev. 2019, 378, 17-31. [CrossRef]

12. Dhaka, S.; Kumar, R.; Deep, A.; Kurade, M.B.; Ji, S.-W.; Jeon, B.-H. Metal-organic frameworks (MOFs) for the removal of emerging contaminants from aquatic environments. Coord. Chem. Rev. 2019, 380, 330-352. [CrossRef]

13. Lv, S.-W.; Liu, J.-M.; Wang, Z.-H.; Ma, H.; Li, C.-Y.; Zhao, N.; Wang, S. Recent advances on porous organic frameworks for the adsorptive removal of hazardous materials. J. Environ. Sci. 2019, 80, 169-185. [CrossRef] [PubMed]

14. Sun, W.; Li, H.; Li, H.; Li, S.; Cao, X. Adsorption mechanisms of ibuprofen and naproxen to UiO-66 and UiO-66-NH2: Batch experiment and DFT calculation. Chem. Eng. J. 2019, 360, 645-653. [CrossRef]

15. Zhuang, S.; Cheng, R.; Wang, J. Adsorption of diclofenac from aqueous solution using UiO-66-type metal-organic frameworks. Chem. Eng. J. 2019, 359, 354-362. [CrossRef]

16. Guo, X.; Kang, C.; Huang, H.; Chang, Y.; Zhong, C. Exploration of functional MOFs for efficient removal of fluoroquinolone antibiotics from water. Microporous Mesoporous Mater. 2019, 286, 84-91. [CrossRef]

17. Chaturvedi, G.; Kaur, A.; Umar, A.; Khan, M.A.; Algarni, H.; Kansal, S.K. Removal of fluoroquinolone drug, levofloxacin, from aqueous phase over iron based MOFs, MIL-100(Fe). J. Solid State Chem. 2020, 281, 121029. [CrossRef]

18. Zhao, R.; Ma, T.; Zhao, S.; Rong, H.; Tian, Y.; Zhu, G. Uniform and stable immobilization of metal-organic frameworks into chitosan matrix for enhanced tetracycline removal from water. Chem. Eng. J. 2020, 382, 122893. [CrossRef]

19. Wu, G.; Ma, J.; Li, S.; Guan, J.; Jiang, B.; Wang, L.; Li, J.; Wang, X.; Chen, L. Magnetic copper-based metal organic framework as an effective and recyclable adsorbent for removal of two fluoroquinolone antibiotics from aqueous solutions. J. Colloid Interface Sci. 2018, 528, 360-371. [CrossRef]

20. Yu, R.; Wu, Z. High adsorption for ofloxacin and reusability by the use of ZIF-8 for wastewater treatment. Microporous Mesoporous Mater. 2020, 308, 110494. [CrossRef]

21. Gao, G.; Xing, Y.; Liu, T.; Wang, J.; Hou, X. UiO-66(Zr) as sorbent for porous membrane protected micro-solid-phase extraction androgens and progestogens in environmental water samples coupled with LC-MS/MS analysis: The application of experimental and molecular simulation method. Microchem. J. 2019, 146, 126-133. [CrossRef]

22. Li, N.; Zhou, L.; Jin, X.; Owens, G.; Chen, Z. Simultaneous removal of tetracycline and oxytetracycline antibiotics from wastewater using a ZIF-8 metal organic-framework. J. Hazard. Mater. 2019, 366, 563-572. [CrossRef] [PubMed]

23. Sun, S.; Yang, Z.; Cao, J.; Wang, Y.; Xiong, W. Copper-doped ZIF-8 with high adsorption performance for removal of tetracycline from aqueous solution. J. Solid State Chem. 2020, 285, 121219. [CrossRef]

24. Kida, K.; Okita, M.; Fujita, K.; Tanaka, S.; Miyake, Y. Formation of high crystalline ZIF-8 in an aqueous solution. CrystEngComm 2013, 15, 1794. [CrossRef]

25. Feng, M.; Zhang, P.; Zhou, H.-C.; Sharma, V.K. Water-stable metal-organic frameworks for aqueous removal of heavy metals and radionuclides: A review. Chemosphere 2018, 209, 783-800. [CrossRef]

26. Park, K.S.; Ni, Z.; Cote, A.P.; Choi, J.Y.; Huang, R.; Uribe-Romo, F.J.; Chae, H.K.; O’Keeffe, M.; Yaghi, O.M. Exceptional chemical and thermal stability of zeolitic imidazolate frameworks. Proc. Natl. Acad. Sci. USA 2006, 103, 10186-10191. [CrossRef]

27. Chen, B.; Yang, Z.; Zhu, Y.; Xia, Y. Zeolitic imidazolate framework materials: Recent progress in synthesis and applications. J. Mater. Chem. A 2014, 2, 16811-16831. [CrossRef]

28. Qiu, L.-G.; Li, Z.-Q.; Wu, Y.; Wang, W.; Xu, T.; Jiang, X. Facile synthesis of nanocrystals of a microporous metal-organic framework by an ultrasonic method and selective sensing of organoamines. Chem. Commun. 2008, 31, 3642-3644. [CrossRef]

29. Lestari, W.W.; Arvinawati, M.; Martien, R.; Kusumaningsih, T. Green and facile synthesis of MOF and nano MOF containing zinc(II) and benzen 1,3,5-tri carboxylate and its study in ibuprofen slow-release. Mater. Chem. Phys. 2018, 204, 141-146. [CrossRef]

30. Yaghi, O.M.; Li, H.; Groy, T.L. Construction of Porous Solids from Hydrogen-Bonded Metal Complexes of 1,3,5-Benzenetricarboxylic Acid. J. Am. Chem. Soc. 1996, 118, 9096-9101. [CrossRef]

31. Pan, Y.; Liu, Y.; Zeng, G.; Zhao, L.; Lai, Z. Rapid synthesis of zeolitic imidazolate framework-8 (ZIF-8) nanocrystals in an aqueous system. Chem. Commun. 2011, 47, 2071. [CrossRef] [PubMed]

32. ASTM International Standard Practice for Determination of Adsorptive Capacity of Activated Carbon by Aqueous Phase Isotherm Technique. ASTM Stand. 2004, 15, 1-4. [CrossRef]

33. Morris, W.; Stevens, C.J.; Taylor, R.E.; Dybowski, C.; Yaghi, O.M.; Garcia-Garibay, M.A. NMR and X-ray Study Revealing the Rigidity of Zeolitic Imidazolate Frameworks. J. Phys. Chem. C 2012, 116, 13307-13312. [CrossRef]

34. Cravillon, J.; Münzer, S.; Lohmeier, S.-J.; Feldhoff, A.; Huber, K.; Wiebcke, M. Rapid Room-Temperature Synthesis and Characterization of Nanocrystals of a Prototypical Zeolitic Imidazolate Framework. Chem. Mater. 2009, 21, 1410-1412. [CrossRef]

35. Ordoñez, M.J.C.; Balkus, K.J.; Ferraris, J.P.; Musselman, I.H. Molecular sieving realized with ZIF-8/Matrimid ${ }^{\circledR}$ mixed-matrix membranes. J. Memb. Sci. 2010, 361, 28-37. [CrossRef] 
36. Jomekian, A.; Behbahani, R.M.; Mohammadi, T.; Kargari, A. Innovative layer by layer and continuous growth methods for synthesis of ZIF-8 membrane on porous polymeric support using poly(ether-block -amide) as structure directing agent for gas separation. Microporous Mesoporous Mater. 2016, 234, 43-54. [CrossRef]

37. Zhang, Y.; Jia, Y.; Hou, L. Synthesis of zeolitic imidazolate framework-8 on polyester fiber for PM 2.5 removal. RSC Adv. 2018, 8 , 31471-31477. [CrossRef]

38. Zhang, M.; Wang, X.; Lin, R.; Liu, Y.; Chen, F.; Cui, L.; Meng, X.; Hou, J. Improving the hydrostability of ZIF-8 membrane by biomolecule towards enhanced nanofiltration performance for dye removal. J. Memb. Sci. 2021, 618, 118630. [CrossRef]

39. Gao, S.; Hou, J.; Deng, Z.; Wang, T.; Beyer, S.; Buzanich, A.G.; Richardson, J.J.; Rawal, A.; Seidel, R.; Zulkifli, M.Y.; et al. Improving the Acidic Stability of Zeolitic Imidazolate Frameworks by Biofunctional Molecules. Chem 2019, 5, 1597-1608. [CrossRef]

40. Ebadi, A.; Soltan Mohammadzadeh, J.S.; Khudiev, A. What is the correct form of BET isotherm for modeling liquid phase adsorption? Adsorption 2009, 15, 65-73. [CrossRef]

41. Barreca, S.; Orecchio, S.; Pace, A. The effect of montmorillonite clay in alginate gel beads for polychlorinated biphenyl adsorption: Isothermal and kinetic studies. Appl. Clay Sci. 2014, 99, 220-228. [CrossRef]

42. Sun, Z.; Liu, H.; Zhou, Y.; Zhao, S.; Li, J.; Wang, X.; Gong, B. A restricted access molecularly imprinted polymer coating on metal-organic frameworks for solid-phase extraction of ofloxacin and enrofloxacin from bovine serum. RSC Adv. 2019, 9, 27953-27960. [CrossRef]

43. Zhang, S.; Wang, Y.; Cao, Z.; Xu, J.; Hu, J.; Huang, Y.; Cui, C.; Liu, H.; Wang, H. Simultaneous enhancements of light-harvesting and charge transfer in UiO-67/CdS/rGO composites toward ofloxacin photo-degradation. Chem. Eng. J. 2020, 381, 122771. [CrossRef] 